\title{
Efficiency and efficacy of planning and care on a post-anesthesia care unit: a retrospective cohort study
}

\author{
Bart van Tunen *i(D, Markus Klimek, Karin Leendertse-Verloop and Robert J. Stolker
}

\begin{abstract}
Background: In the post-anesthesia care unit in our hospital, selected postoperative patients receive care from anesthesiologists and nursing staff if these patients require intensive hemodynamic monitoring or treatment to stabilize vital functions (e.g., vasopressor use and mechanical ventilation support) during a one-night admission. We investigated the agreement between elective preoperative planning for post-anesthesia care unit admission and the postoperative reality, along with the consequences of planning failures.

Methods: Data from records for 479 consecutive patients from June 1 to November 30, 2014, in a tertiary referral hospital were reviewed and analyzed. All patients admitted to PACU were included, along with patients scheduled to be referred to PACU but ultimately transferred to another ward. The primary outcome was the efficiency of planning PACU admission for elective patients. Secondary outcomes included secondary admissions to PACU or the intensive care unit (ICU) and 30-day morbidity and mortality.

Results: Of the 479 included patients, 342 (71\%) were admitted per preoperative planning. Five patients (1\%) needed cardiopulmonary resuscitation, and six (1\%) did not survive the follow-up period. Patients admitted to PACU because of a shortage of beds in the ICU had the highest readmission (20\%) and mortality rates (20\%) $(P=0.01)$.

Conclusions: Preoperative planning for PACU admission was off-target for $29 \%$. However, efficient care always takes precedence over efficient planning. In particular, downgrading patients to PACU because of a shortage of beds in the ICU was associated with a mortality increase.
\end{abstract}

Keywords: Anesthesia recovery period, Postoperative care, Mortality, Patient safety, Management of logistics, Queuing

\section{Background}

In the post-anesthesia care unit (PACU) in our hospital, selected postoperative patients receive care from anesthesiologists and nursing staff if these patients require intensive hemodynamic monitoring or treatment to stabilize vital functions (e.g., vasopressor use and mechanical ventilation support) during a one-night admission [1]. The level of care in the PACU is lower than that provided in the ICU but higher than in

\footnotetext{
* Correspondence: b.vantunen@erasmusmc.nl

Department of Anesthesiology, Erasmus MC, University Medical Center Rotterdam, P.O. Box 2040, 3000, CA, Rotterdam, the Netherlands other high-care units or common wards. PACUs have been established to improve OR logistics in times of chronically overloaded ICUs. In our hospital, preoperative planning for PACU admission is completely independent from logistics for the routine postoperative recovery ward and ICU planning.

Recent evidence suggests that both surgical procedure and the quality of postoperative care and complication management are major factors in patient outcomes $[2$, 3]. We view the availability of our PACU, as an opportunity to treat these patients in a way that enhances safety. 
We hypothesized that preoperative planning of elective surgery according to our inclusion and exclusion criteria (Appendices 1a and 1b) would result in an optimal occupation of about $85 \%$ of our PACU beds, which is based on internal business plans and estimations according to the Queuing theory [4-6]. Our goal was to facilitate the maximum number of elective procedures while minimizing the cost of empty beds without risking a backlog of other elective surgeries.

\section{Methods}

The study was approved by the Medical and Ethical Review Committee of our university medical center (number MEC-2016-014). The STROBE Statement checklist for cohort studies was followed in the writing of this manuscript.

The design of our PACU resulted from the need for a better perioperative flow for elective surgery. Our PACU consists of five beds; during our study period, a total of 562 PACU beds were available. In our perioperative planning, we work with capacity slots on PACU. These slots are made available for the different surgical disciplines according to a schedule, which is communicated about 6 weeks ahead of date. On our preoperative assessment policlinic, we plan our patients for postoperative admission location: general ward, PACU or ICU. On the day before, the OR planner and one of our staff anesthesiologists check all planned surgery and the postoperative admission location of all patients. According to these strictly applied planning rules, the number of patients planned for surgery on the same day with a documented indication for PACU admission may never be higher than the five beds we have. The selected patients, undergoing major but mostly uncomplicated interventions, as well as patients with particular comorbidities, are not admitted to an ICU. In a PACU, patients can receive a more intensive level of monitoring and care than in a general ward while the ICU burden can be relieved. However, in the ICU, a doctor is on the ward 24/7, whereas the medical care on specialist level in our PACU is provided on the ward from 8 a.m. to 8 p.m., with clinicians on call in-house during night. The nurse: patient ratio on our PACU is 1: 2 (same as on ICU) and paramedics such as a physiotherapist or dietist can be consultated during working hours from 9 a.m. to 5 p.m.

In this cohort study, all records for consecutive patients admitted to the PACU in our tertiary referral hospital between June 1 and November 30, 2014, were retrospectively reviewed. Cardiac and pulmonary surgeries were performed in our cardiothoracic surgery center, so these patients were not included in this study. All patients sent to the PACU were included, as were those who were scheduled to be admitted to the PACU but were placed on another ward.
Based on clinical experience, criteria for admission to PACU in our hospital consisted of anesthesiological indications, surgical indications, and/or comorbidities (Appendix 1a). Reasons for excluding patients are summarized in Appendix 1b. Elective surgery was defined as all planned surgery, as we could specifically study this elective surgery cohort, we excluded all emergency patients undergoing unplanned surgery within $24 \mathrm{~h}$ after hospital admission. Criteria for PACU discharge to the ward were a stable hemodynamic and respiratory status without vasopressor support and no need for invasive monitoring or treatment.

We classified included patients as follows: PACU planned/admitted (Group I); PACU planned/not admitted (Group II); and PACU not planned/admitted (Group III). For this third group, we subclassified patients further as upgraded to PACU because of anesthesiology- and/or surgery-related reasons/complications (Group III-a) or downgraded to PACU because of a full ICU (Group III-b).

The primary outcome of this study was the planning efficiency of elective patient admissions to PACU. Secondary outcomes were secondary admissions to PACU or ICU, cardiopulmonary resuscitation (CPR), and mortality. We also compared the mortality of patients admitted to the PACU with elective postoperative patients admitted to the ICU. We used a 30-day follow-up period, which is an established indicator of quality and safety of perioperative care [7].

\section{Statistical analysis}

All data were analyzed using the Statistical Package for the Social Sciences (SPSS) version 22.0 (SPSS, Chicago, Ill., USA). Normality of continuous data was tested using the Shapiro-Wilk test. Continuous data are reported as means and standard deviation (parametric data) or as medians and percentiles (non-parametric data); categorical data are reported as numbers with percentages.

To compare outcomes between patients who were not planned for PACU but upgraded or downgraded to it, we used a contingency table and analyzed the results with Fisher's exact test. Because of the scientific discussions about the need of multiple test adjustments for exploratory study design regarding secondary outcomes, we did not determine a specific level of significance [8].

\section{Results}

From June 1 to November 30, a total of 538 patients (from a total volume of 4270 procedures performed) were admitted to the PACU or planned for admission. Of these, 59 patients were excluded from these analyses: 54 were emergency patients, 4 were admitted for measurement of intracranial pressure, and one patient had a protected electronic file, precluding chart review. Thus, we analyzed data for 479 patients (Fig. 1). Because of cancellation or delay of their procedure, 19 patients were 


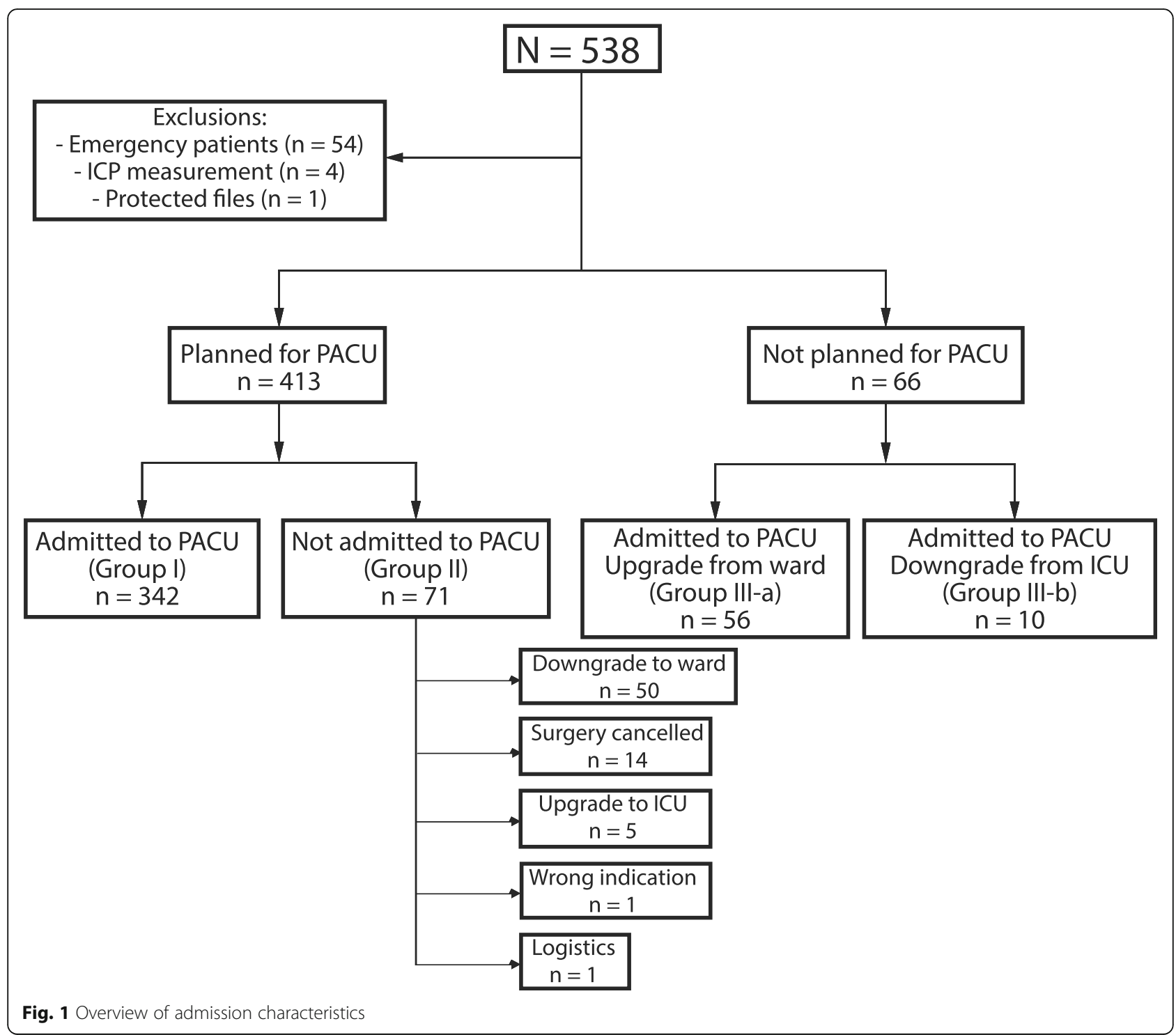

included more than once in the database because they had more than one PACU indication. An overview of patient characteristics is shown in Table 1.

\section{Elective patients scheduled for PACU admission (groups I \& II)}

Of the 479 included patients, a total of 342 patients (71\%) were planned for PACU admission and admitted to $\mathrm{PACU}$ (planned/admitted = Group I). Another $71 \mathrm{pa}-$ tients $(15 \%)$ were preoperatively planned for PACU, but not admitted postoperatively $($ planned $/$ not admitted $=$ Group II), see Fig. 1.

An overview of the most common preoperative surgical and anesthesiological indications for a planned PACU admission according to our protocol is given in Table 2. Because some patients had more than one indication, 498 indications for PACU admission
Table 1 Patient characteristics

\begin{tabular}{|c|c|}
\hline $\mathrm{N}$ & 479 \\
\hline \multicolumn{2}{|l|}{ Sex (\% of total cohort) } \\
\hline Men & $280(59 \%)$ \\
\hline Women & $199(41 \%)$ \\
\hline Median age, years $\left(P_{25}-P_{75}\right)$ & $61(49-70)$ \\
\hline Mean height, cm ( \pm SD) & $174( \pm 11)$ \\
\hline Median weight, $\mathrm{kg}\left(\mathrm{P}_{25}-\mathrm{P}_{75}\right)$ & $81(70-94)$ \\
\hline Median BMI, kg.m ${ }^{-2}\left(P_{25}-P_{75}\right)$ & $26(24-31)$ \\
\hline \multicolumn{2}{|c|}{$\mathrm{ASA}^{\mathrm{a}}$ classification (\% of total cohort) } \\
\hline । & $48(10 \%)$ \\
\hline$\|$ & $193(40 \%)$ \\
\hline$\|$ & $218(46 \%)$ \\
\hline IV & $20(4 \%)$ \\
\hline
\end{tabular}

${ }^{\mathrm{a} A m e r i c a n ~ S o c i e t y ~ o f ~ A n e s t h e s i o l o g i s t s ~}$ 
Table 2 Elective patients scheduled for PACU admission

\begin{tabular}{|c|c|c|c|}
\hline Preoperative admission indication & $\begin{array}{l}\text { Indications, total cohort } \\
(\boldsymbol{N}=413)\end{array}$ & $\begin{array}{l}\text { Indications, planned and } \\
\text { admitted patients (Group I) } \\
(\boldsymbol{n}=342)\end{array}$ & $\begin{array}{l}\text { Indications, planned but not } \\
\text { admitted patients (Group II) } \\
(\boldsymbol{n}=71)\end{array}$ \\
\hline a. Surgical indications ${ }^{a}(n=229)$ & 229 & 204 & 25 \\
\hline Supratentorial craniotomy (including open biopsy) & 89 & 82 & 7 \\
\hline Whipple operation & 29 & 25 & 4 \\
\hline Hemihepatectomy & 26 & 20 & 6 \\
\hline $\begin{array}{l}\text { Kidney transplantation + comorbidity or need for } \\
\text { vasopressive support }\end{array}$ & 16 & 15 & 1 \\
\hline Awake craniotomy & 11 & 10 & 1 \\
\hline b. Anesthesiological indications ( $n=47$ ) & 55 & 38 & 17 \\
\hline (Expected) perioperative pulmonary or cardiac complications & 44 & 30 & 14 \\
\hline (Expected) postoperative catecholamine support & 6 & 5 & 1 \\
\hline (Expected) postoperative airway complications & 5 & 3 & 2 \\
\hline c. Comorbidities ( $n=99$ ) & 171 & 137 & 34 \\
\hline OSA syndrome & 70 & 54 & 16 \\
\hline Heart failure & 67 & 54 & 13 \\
\hline Chronic obstructive pulmonary disease & 17 & 14 & 3 \\
\hline Morbid obesity & 14 & 12 & 2 \\
\hline Cervical paraplegia & 2 & 2 & 0 \\
\hline Unregulated diabetes mellitus & 1 & 1 & 0 \\
\hline d. Other (not listed in Table 1) $(\boldsymbol{n}=\mathbf{3 8}$ ) & 43 & 34 & 9 \\
\hline Minor surgery in frail patients & 17 & 14 & 3 \\
\hline Rare major high-risk surgery & 18 & 13 & 5 \\
\hline Congenital syndromes & 5 & 4 & 1 \\
\hline Bronchoalveolar lavage & 3 & 3 & 0 \\
\hline Total $(n=413)$ & 498 & 413 & 85 \\
\hline
\end{tabular}

${ }^{a}$ Most relevant surgical indications

existed for the 413 patients who were planned preoperatively (Group I + II). Of these 413 patients, the indication for 184 patients (45\%) was anesthesiological, comorbidity, or other reason (Table 2, b-d) rather than type of surgery. We also counted 43 other indications that are not mentioned in Appendix 1a (e.g., minor/moderate surgery in frail patients and rare, unlisted major high-risk procedures). Frail patients were considered as high risk and were planned for PACU admission. Frailty was defined individually by the screening anesthesiologist in the preoperative outpatient department, based on declines in physiologic reserve and function across multi-organ systems, leading to increased vulnerability for adverse health outcomes [9]. In a subgroup analysis of these 43 patients, we could not identify any specific listed risk factor.

The biggest contributor to downgrading in the PACU planned/not admitted group (Group II) was obstructive sleep apnea (OSA) syndrome as the preoperative indication. Most patients were not admitted because the attending anesthesiologist assessed the early postoperative condition as better than expected and agreed with admission to the general ward.

\section{Elective patients not scheduled for PACU admission, but subsequently admitted to PACU (group III)}

Of the 137 patients (29\%) that were not planned correctly, 66 patients $(14 \%)$ were not scheduled preoperatively for PACU admission but were admitted (not planned/admitted $=$ Group III), see Fig. 1 . Fourteen of these underwent surgery associated with one of the PACU indications listed in Appendix 1a and should have been scheduled preoperatively to conform to protocol. Focusing on the anesthesiological reasons, two patients diagnosed with cardiac comorbidities underwent kidney transplantation, one patient with cardiac arrhythmias and decompensation underwent carotid surgery, and the other patient underwent cervical spondylodesis.

Forty-two patients who were not planned for PACU but upgraded to it from the general ward underwent 
heterogeneous types of operations showing perioperative complications, such as suspect changes in electrocardiography or arrhythmia $(n=7)$, need for catecholamine support because of prolonged intraoperative hypotension $(n=6)$, metabolic acidosis and electrolyte disorders $(n=$ 5), pulsoximetric saturation drops $(n=3)$, and massive perioperative blood loss $(n=1)$.

Ten patients were planned for ICU admission but were downgraded to PACU immediately postoperative because of unavailable ICU beds. In these cases, at surgery start, a postoperative bed was available in ICU but was occupied by an emergency patient during the procedure. With agreement from both the attending anesthesiologist and surgeon, in these cases, the patient planned for ICU was not transferred to another hospital but instead was admitted to PACU with back-up support of the intensivist, if necessary.

\section{Follow-up}

Of 413 patients scheduled for admission to PACU, 28 (7\%) were secondarily admitted to ICU or readmitted to PACU within 30 days after the initial postoperative admission (Table 3), and another three were admitted a third time within that 30-day period. Secondary and tertiary admissions were mainly because of cardiovascular $(n=10)$ or surgical reasons $(n=7)$, such as bleeding or ileus. Other reasons were pulmonary $(n=5)$, neurologic $(n=5)$, infectious $(n=5)$, or metabolic $(n=1)$. Of the three patients admitted a third time, two had developed postoperative complications and underwent another surgery, followed by a second admission to PACU. The third patient was readmitted for complex pain treatment.

Subgroup analysis showed that the patients who were admitted to PACU because of unavailable beds in the ICU (group III-b) had the highest readmission rate, at $20 \%$ (Table 3).

Of all 479 inclusions, five patients (1\%) underwent CPR during the 30-day follow-up period after surgery, two of them unplanned transfers to PACU. Another six patients (1\%) did not survive this period (Table 4), two of them among the patients who were downgraded from ICU, for a rate of $20 \%(2 / 10)$ in this group. This mortality rate in group III-b was higher than among patients who were planned for and admitted to PACU (group I, 4/342 (1\%), $P=0.01$ ), planned for and not admitted to PACU (group II, 0/71 (0\%), $\mathrm{P}=0.01$ ), and not planned for but upgraded to PACU (group III-a, 0/56 (0\%), $P=$ 0.02).

\section{Discussion}

In this study, we analyzed data for 479 patients with a preoperative indication for admission to PACU or with an unplanned PACU admission. Of these, 137 patients (29\%) had not been planned correctly. The proportion of these incorrect planned patients is roughly unchanged throughout the study period (Appendix 2). Most of these cases of unplanned PACU admission would have been unforeseen, but 14 of them could have been planned correctly if our guidelines had been followed.

Although the primary outcome of efficiency of planning for PACU admission was only $71 \%$, secondary outcomes (readmissions, CPR, and mortality) were relatively low in the group planned for PACU but not admitted. These results suggest that the decision to place these patients on the general ward instead was appropriate. However, for each of these 71 patients planned for PACU but not admitted, a dispensable bed was reserved and another elective surgery might not have been planned that day. Most patients in this group were indicated for PACU because of OSA, which is considered a legitimate reason for PACU admission because of the increased risks for postoperative complications [10]. Multiple studies highlight the fact that most respiratory complications from OSA syndrome manifest in the first $24 \mathrm{~h}$ postoperatively $[11,12]$, suggesting that its inclusion on the PACU indications list is appropriate.

Seventeen patients considered to be frail were planned for and admitted to PACU without an indication on the

Table 3 Secondary and tertiary PACU and ICU admissions

\begin{tabular}{|c|c|c|c|c|c|}
\hline Readmission & Total cohort $(\boldsymbol{N}=479)$ & $\begin{array}{l}\text { PACU: planned/ } \\
\text { admitted (Group I) } \\
(\boldsymbol{n}=342)\end{array}$ & $\begin{array}{l}\text { PACU: planned/not } \\
\text { admitted (Group II) } \\
(\boldsymbol{n}=71)\end{array}$ & $\begin{array}{l}\text { PACU: not planned/ } \\
\text { admitted instead of } \\
\text { general ward } \\
\text { (Group III-a) } \\
(\boldsymbol{n}=56)\end{array}$ & $\begin{array}{l}\text { PACU: not planned/ } \\
\text { admitted instead of } \\
\text { ICU (Group III-b) } \\
(\boldsymbol{n}=10)\end{array}$ \\
\hline Secondary admission & 28 & 19 & 3 & 4 & 2 \\
\hline PACU & 3 & 2 & 0 & 1 & 0 \\
\hline $\mathrm{ICU}$ & 25 & 17 & 3 & 3 & 2 \\
\hline Tertiary admission & 3 & 3 & 0 & 0 & 0 \\
\hline PACU & 1 & 1 & 0 & 0 & 0 \\
\hline $\mathrm{ICU}$ & 2 & 2 & 0 & 0 & 0 \\
\hline Total (\% of total group number) & $31(6 \%)$ & $22(6 \%)$ & $3(4 \%)$ & $4(7 \%)$ & $2(20 \%)$ \\
\hline
\end{tabular}


Table 4 CPR and mortality

\begin{tabular}{|c|c|c|c|c|c|}
\hline Outcome & Total cohort $(\boldsymbol{N}=479)$ & $\begin{array}{l}\text { PACU: planned/ } \\
\text { admitted (Group I) } \\
(\boldsymbol{n}=342)\end{array}$ & $\begin{array}{l}\text { PACU: planned/not } \\
\text { admitted (Group II) } \\
(\boldsymbol{n}=71)\end{array}$ & $\begin{array}{l}\text { PACU: not planned/ } \\
\text { admitted instead of } \\
\text { general ward } \\
\text { (Group III-a) } \\
(\boldsymbol{n}=56) \\
\end{array}$ & $\begin{array}{l}\text { PACU: not planned/ } \\
\text { admitted instead of } \\
\text { ICU (Group III-b) } \\
(\boldsymbol{n}=10)\end{array}$ \\
\hline$\overline{C P R}$ & 5 & 3 & 0 & 2 & 0 \\
\hline Death & 6 & 4 & 0 & 0 & 2 \\
\hline Total (\% of total group number) & $11(2 \%)$ & $7(2 \%)$ & $0(0 \%)$ & $2(4 \%)$ & $2(20 \%)$ \\
\hline
\end{tabular}

prespecified list of indications (Appendix 1a). Admission indications should be revised with the inclusion of a clear definition of frailty, using a validated scoring system such as the Risk Analysis Index, the Hopkins Frailty Score, or Risk Stratification Indices [13-15].

Readmission is associated with adverse health events during the same hospitalization, and mortality rates are up to 11 times higher in these patients than in those who are not readmitted [16-19]. Furthermore, postoperative complications have been identified as a major contributor to short- and long-term mortality, and these patients are at higher risk of intervention from an emergency team [20-22]. Among patients not planned for PACU but admitted, the high number of readmissions to PACU and secondary/tertiary admissions to ICU, together with the highest mortality rate among those shifted to PACU from ICU, stresses the need to admit patients to the right unit. However, according to Warner et al., more than one third of major morbidity occurs 48 $\mathrm{h}$ or more after surgery [23], making a zero readmission rate quite difficult to achieve.

Regarding multiple testing for our secondary outcomes, discussion exists for adjusting the level of significance in exploratory study design. Therefore we did not determine a strict level of significance in our methods. However, no matter what level of significance is used, we found an increased mortality rate in the patients shifted from ICU to PACU (group III-b) and there is a clear trend that the difference between these patients and the patients from groups I $(P=0.01)$, II $(P=0.01)$ and III-a $(P=0.02)$ can be considered significant. During the same 6-month period, 222 elective postoperative (non-cardiac surgery) patients were admitted to ICU. Of this group, six (3\%) died. When we compare the mortality of these patients with those in the current study who were shifted from ICU to PACU, mortality was higher in the latter group $(P=0.04)$. The shift of a patient from ICU to PACU means reduced clinician presence during the nighttime hours, making such a shift potentially riskier for the patient. This risk should be considered in making such decisions. Our results suggest that moving patients planned for ICU to PACU is highly undesirable, but the retrospective nature of this study precludes further conclusions or recommendations.
Our PACU differs in important ways from those in some other countries. As mentioned the introduction, our PACU provides intensive hemodynamic monitoring and treatment to stabilize vital functions during a onenight admission for selected patients undergoing highrisk surgery or who have high-risk comorbidity. This mission differs significantly from a phase I PACU (which in our hospital is known as the recovery ward), where any postoperative patient recovers from surgery until they are discharged to an alternative location (e.g., a phase II discharge unit) the same day [24]. With this clarification, it remains of utmost importance to admit the right patient to the right unit and to prevent logistical issues (such as unavailable ICU beds) that require large changes to organizational processes.

Only three other studies have focused on this specific subject and are available for comparison. Irone et al. included 1142 patients admitted to a comparable PACU [25]. In their study, hospital mortality was much higher (5.6\%) than in our patient group, and they faced ICUrelated logistic issues for $26 \%$ of their patients (compared to $0.02 \%$ or $10 / 479$ in our study). Their findings, however, are in agreement with ours in that it is a challenge for intensive care medicine to identify with sufficient lead time which patients are vulnerable.

Bing-Hua found that prolonged waiting $(\geq 6 \mathrm{~h})$ in a recovery ward such as one type of PACU is associated with higher ICU mortality [26]. These results also are in agreement with ours. This apparently common phenomenon of a shortage of ICU beds highlights the importance of reliable preoperative planning.

According to Wickboldt et al., the duration of PACU stay is an independent risk factor for mortality and might be a surrogate marker for early postoperative adverse events or complications [27]. In our study, eight patients stayed for more than 1 day in the PACU. None of them were readmitted or underwent CPR, but one patient died 3 days after surgery because of a major cerebrovascular infarction.

\section{Limitations}

We want to highlight a few limitations of our study, the most relevant of which are related to its retrospective design. For logistical reasons, a sample size calculation 
was not possible because of a lack of international literature, so we decided that a 6-month retrospective design would be representative and sufficient. When our study was registered at our hospital's ethical committee in 2016, the study period from June to November 2014 was considered as most representative with regards to available beds, number of admissions and the nurse: patient ratio. Furthermore, in contrast to later periods, during these 6 months no major changes in the processes were implemented (e.g. later we had implementation of a new electronic patient-data-system, renovation and even moving of the ward). So, whilst these data might seem old, they still reflect our current way of planning and admitting patients to our PACU and we are convinced that the results are easy transferable to today's situation.

Furthermore, this is a single-center study in a university hospital based on our local policy and practices, which cannot easily be transferred to other hospital settings, and the small number of included patients precludes strong conclusions. However, we believe that the results presented here can be useful for colleagues working in different settings, as well.

Despite these limitations, this study highlights the need for reliable planning of the postoperative admission location and the effect of any deviation from this planning. It is important to recognize that a well-considered deviation of the planned admission location - although it might seem to limit planning efficiency - supports efficient, safe, patient-directed and goal-directed highquality care, as described by the World Health Organization, even if this results in an empty bed on the PACU [28].

\section{Conclusion}

The appropriate postoperative destination of almost 29\% of all patients included in this study had not been planned correctly. This level of inefficiency traces to incorrect preoperative assessment by the surgeon or anesthesiologist, an incomplete list of PACU indications, logistic issues related to ICU bed availability, and changes in the perioperative course. However, it is important to emphasize that efficient care always takes precedence over efficient planning. Downgrading a postoperative patient from PACU to general ward based on decision by the anesthesiologist in charge creates no additional risk for the patient and enhances efficiency of care. On the other hand, despite the small number of patients, we can conclude that there is a clear trend $(P=$ $0.01)$ that an unplanned shift from ICU to PACU seems to be associated with an increase in mortality risk.

\section{Implications}

The findings presented here can be used by others to review (and hopefully improve) their own practice concerning the perioperative patient flow. This begins with the identification and selection of patients needing a more intense level of postoperative care than a general ward can provide, but includes also the optimization of the logistics around these beds providing the higher level of care. Our findings highlight the fact that patients downgraded from ICU to PACU are vulnerable and prone for complications and mortality. This situation should be prevented whenever possible, and otherwise deserves special attention from the responsible physicians. However, shortage of beds in ICUs is an increasing common phenomenon worldwide and management of these logistic issues and its impact on the quality of care should be addressed by future research.

\section{Supplementary information}

Supplementary information accompanies this paper at https://doi.org/10. 1186/s12913-020-05376-2.

\section{Additional file 1. Appendices.}

\section{Abbreviations}

PACU: Post Anesthesia Care Unit; ICU: Intensive Care Unit; CPR: Cardiopulmonary resuscitation; OSA: Obstructive sleep apnea; OR: Operation Room

\section{Acknowledgements}

We acknowledge San Francisco Edit for their services in reviewing the English language, style, and presentation of our manuscript. Statistical advice and support by dr. Sanne E. Hoeks was greatly appreciated.

\section{Authors' contributions}

All authors (BT, MK, KLV, RJS) contributed to the study conception and design and material preparation. Data collection and analysis were performed by BT, MK and RJS. The first draft of the manuscript was written by BT and all co-authors (MK, KLV, RJS) commented on previous versions of the manuscript. All authors read and approved the final manuscript.

Funding

Not applicable.

\section{Availability of data and materials}

The datasets used and/or analysed during the current study are available from the corresponding author on reasonable request.

\section{Ethics approval and consent to participate}

The study was approved by the Medical and Ethical Review Committee of Erasmus Medical Center (reference number MEC-2016-014).

Consent for publication

Not applicable.

Competing interests

The authors declare that they have no competing interests.

Received: 28 February 2020 Accepted: 28 May 2020

Published online: 22 June 2020

\section{References}

1. Anesthesiologie.nl (2011). Dutch Society of Anesthesiology: PACU Vision Document. [online] Available at: https://www.anesthesiologie.nl/publicaties/ visiedocument-pacu . Accessed 1 May 2020.

2. Boehm O, Baumgarten G, Hoeft A. Epidemiology of the high-risk population: perioperative risk and mortality after surgery. Curr Opin Crit Care. 2015;21(4):322-7. 
3. Ghaferi AA, Birkmeyer JD, Dimick JB. Hospital volume and failure to rescue with high-risk surgery. Med Care. 2011;49(12):1076-81.

4. Bagust A, Place M, Posnett J. Dynamics of bed use in accommodating emergency admissions: stochastic simulation model. BMJ. 1999:319(7203): 155-8.

5. McManus M, Long M, Cooper A, Litvak E. Queuing theory accurately models the need for critical care resources. Anesthesiology. 2004;100(5):1271-6.

6. De Bruin A, Bekker R, Van Zanten L, Koole G. Dimensioning hospital wards using the Erlang loss model. Ann Oper Res. 2009;178(1):23-43.

7. Dimick JB, Welch HG, Birkmeyer JD. Surgical mortality as an indicator of hospital quality: the problem with small sample size. JAMA. 2004;292(7): 847-51.

8. Bender R, Lange S. Adjusting for multiple testing - when and how? I Clin Epidemiol. 2001;54(4):343-9.

9. Chen X, Mao G, Leng SX. Frailty syndrome: an overview. Clin Interv Aging 2014;9:433-41

10. Lipford MC, Ramar K, Surani SR. Obstructive sleep apnea in the perioperative setting: complications and management strategies. Hosp Pract. 2015;43(1):56-63.

11. Weingarten TN, Warner LL, Sprung J. Timing of postoperative respiratory emergencies: when do they really occur? Curr Opin Anaesthesiol. 2017; 30(1):156-62.

12. Lee LA, Caplan RA, Stephens LS, Posner KL, Terman GW, Voepel-Lewis T, et al. Postoperative opioid-induced respiratory depression: a closed claims analysis. Anesthesiology. 2015;122(3):659-65.

13. Hall DE, Arya S, Schmid KK, Carlson MA, Lavedan P, Bailey TL, et al. Association of a Frailty Screening Initiative with Postoperative Survival at 30, 180, and 365 days. JAMA Surg. 2017;152(3):233-40.

14. Revenig LM, Canter DJ, Taylor MD, Tai C, Sweeney JF, Sarmiento JM, et al. Too frail for surgery? Initial results of a large multidisciplinary prospective study examining preoperative variables predictive of poor surgical outcomes. J Am Coll Surg. 2013;217(4):665-70.

15. Sessler DI, Sigl JC, Manberg PJ, Kelley SD, Schubert A, Chamoun NG. Broadly applicable risk stratification system for predicting duration of hospitalization and mortality. Anesthesiology. 2010;113(5):1026-37.

16. Elliott M. Readmission to intensive care: a review of the literature. Aust Crit Care. 2006;19(3):96-8 100-4.

17. Kaben A, Correa F, Reinhart K, Settmacher U, Gummert J, Kalff R, et al. Readmission to a surgical intensive care unit: incidence, outcome and risk factors. Crit Care. 2008;12(5):123.

18. Rosenberg AL, Watts C. Patients readmitted to ICUs: a systematic review of risk factors and outcomes. Chest. 2000;118(2):492-502.

19. Frost SA, Alexandrou E, Bogdanovski T, Salamonson Y, Davidson PM, Parr $\mathrm{MJ}$, et al. Severity of illness and risk of readmission to intensive care: a metaanalysis. Resuscitation. 2009;80(5):505-10.

20. Khuri SF, Henderson WG, DePalma RG, Mosca C, Healey NA, Kumbhani DJ, et al. Determinants of long-term survival after major surgery and the adverse effect of postoperative complications. Ann Surg. 2005;242(3):326-41.

21. Ferraris VA, Bolanos M, Martin JT, Mahan A, Saha SP. Identification of patients with postoperative complications who are at risk for failure to rescue. JAMA Surg. 2014;149(11):1103-8.

22. Tjeertes EK, Ultee KH, Stolker RJ, Verhagen HJ, Bastos Goncalves FM, Hoofwijk AG, et al. Perioperative complications are associated with adverse Long-term prognosis and affect the cause of death after general surgery. World I Surg. 2016;40(11):2581-90.

23. Warner MA, Shields SE, Chute CG. Major morbidity and mortality within 1 month of ambulatory surgery and anesthesia. JAMA. 1993;270(12):1437-41.

24. Ehrenfeld JM, Dexter F, Rothman BS, Minton BS, Johnson D, Sandberg WS, et al. Lack of utility of a decision support system to mitigate delays in admission from the operating room to the postanesthesia care unit. Anesth Analg. 2013;117(6):1444-52.

25. Irone M, Parise N, Bolgan I, Campostrini S, Dan M, Piccinni P. Assessment of adequacy of ICU admission. Minerva Anestesiol. 2002;68(4):201-7.

26. Bing-Hua YU. Delayed admission to intensive care unit for critically surgical patients is associated with increased mortality. Am J Surg. 2014;208(2):268-74.

27. Wickboldt N, Haller G, Delhumeau C, Walder B. A low observed-to-expected postoperative mortality ratio in a Swiss high-standard peri-operative care environment - an observational study. Swiss Med Wkly. 2015;145:w14205.

28. World Health Organization (2019). What is Quality of Care and why is it important?. [online] Available at: https://www.who.int/maternal_child_ adolescent/topics/quality-of-care/definition/en/ . Accessed 1 May 2020.

\section{Publisher's Note}

Springer Nature remains neutral with regard to jurisdictional claims in published maps and institutional affiliations.
Ready to submit your research? Choose BMC and benefit from:

- fast, convenient online submission

- thorough peer review by experienced researchers in your field

- rapid publication on acceptance

- support for research data, including large and complex data types

- gold Open Access which fosters wider collaboration and increased citations

- maximum visibility for your research: over $100 \mathrm{M}$ website views per year

At $\mathrm{BMC}$, research is always in progress.

Learn more biomedcentral.com/submissions 